\title{
Microstructural Characterization and Phase Separation Sequences During Solidification of $\mathrm{Ni}_{3} \mathrm{Al}$-Based Superalloy
}

\author{
Jing $\mathrm{Wu}^{1} \cdot$ Yong-Chang Liu ${ }^{1}$ Chong $\mathrm{Li}^{1} \cdot$ Xing-Chuan $\mathrm{Xia}^{1} \cdot$ Yu-Ting Wu ${ }^{1} \cdot$ Hui-Jun $\mathrm{Li}^{1} \cdot$ Hai-Peng $\mathrm{Wang}^{2}$
}

Received: 8 April 2017/Revised: 2 May 2017/Published online: 3 August 2017

(c) The Chinese Society for Metals and Springer-Verlag GmbH Germany 2017

\begin{abstract}
As-cast microstructure of a designed polycrystalline $\mathrm{Ni}_{3} \mathrm{Al}$-based superalloy is characterized using optical microscope, scanning electron microscope, transmission electron microscope equipped with selected area diffraction system, and the intermetallic phase transformations involved during solidification process are determined based on thermal analysis measurements. The as-cast microstructure is mainly composed of $80.63 \mathrm{vol} \%$ dendritic and $19.37 \mathrm{vol} \%$ interdendritic phases, and the dendrite is identified as quasi-cuboidal $\gamma_{\mathrm{I}}^{\prime}$ phase connected by $\gamma$-channels where ultrafine $\gamma_{\text {II }}^{\prime}$ particles are distributed, and the interdendritic phases are determined as $\gamma^{\prime}-\gamma$ eutectic structure consisting of $\gamma_{\mathrm{E}}$ phase with dotted quasi-spherical $\gamma_{\mathrm{E}}^{\prime}$ particles. During solidification, the dendrite firstly nucleates from liquid melt near $1348{ }^{\circ} \mathrm{C}$; subsequently, the residual liquidoid is transformed into interdendritic phases around $1326{ }^{\circ} \mathrm{C}$. Afterward, $\gamma^{\prime}$ phase will precipitate from dendritic $\gamma$ matrix with two-stage characteristics, resulting in the distinct precipitation of $\gamma_{\mathrm{I}}^{\prime}$ and $\gamma_{\mathrm{II}}^{\prime}$ phases when approaching to 1190 and $1043{ }^{\circ} \mathrm{C}$, respectively. The corresponding transformations involved during the solidification process can be translated as:
\end{abstract}

Liquidoid $\left\{\begin{array}{c}\text { Dendrite }\left(\gamma_{\mathrm{D}}\right) \rightarrow \gamma_{\mathrm{I}}^{\prime}+\gamma \text { (channel) } \\ (80.63 \%) \\ \begin{array}{c}\text { Residual liquidoid } \\ (19.37 \%)\end{array}\end{array} \begin{array}{c}\text { Interdenrite } \\ \left(\gamma_{\mathrm{E}}^{\prime}-\gamma_{\mathrm{E}} \text { eutectic }\right)\end{array}\right\}$ As-cast

KEY WORDS: $\gamma^{\prime}$ phase; Microstructure; Transformation; Solidification; $\mathrm{Ni}_{3} \mathrm{Al}$-based superalloy

Available online at http://link.springer.com/journal/40195

Yong-Chang Liu

licmtju@163.com

$\triangle$ Chong Li

lichongme@tju.edu.cn

1 State Key Lab of Hydraulic Engineering Simulation and Safety, School of Materials Science and Engineering, Tianjin University, Tianjin 300354, China

2 Department of Applied Physics, School of Science, Northwestern Polytechnical University, Xi' an 710129, China

\section{Introduction}

$\mathrm{Ni}_{3} \mathrm{Al}$-based superalloys are the widely used high-temperature structural materials in manufacture of aero-engines owing to their unique combination of high strength, creep resistance, wear resistance as well as fatigue properties at elevated temperature up to $1100{ }^{\circ} \mathrm{C}$ [1-3]. The excellent mechanical properties are primarily derived from high volume fraction (above $80 \%$ ) of $\mathrm{L1}_{2}$-type $\gamma^{\prime}-\mathrm{Ni}_{3} \mathrm{Al}$ intermetallic phase possessing anomalous yield behavior, which 
was firstly discovered by Westbrook [4]. Due to the enhanced critical properties required for aero-engines, the service temperature of traditional nickel-based superalloys has approached closed to the melting point $[5,6]$. Therefore, along with the development of advanced aero-engines, the $\mathrm{Ni}_{3} \mathrm{Al}$-based superalloys possessing higher enduring temperature, lower density and outstanding mechanical properties are developed and expected to apply as a new generation of ultrahigh-temperature structural materials, replacing part of traditional nickel-based superalloys used as the hot-end components in the advanced aero-engines [7].

Due to their excellent high-temperature properties, the extreme brittleness caused by intergranular fracture has seriously hindered the development of $\mathrm{Ni}_{3} \mathrm{Al}$-based superalloys. Aoki and Izumi [8] found that the brittleness in the $\mathrm{L}_{2}$ intermetallic compound $\mathrm{Ni}_{3} \mathrm{Al}$ could be overcome dramatically by microalloying with traces of boron, on the order of $0.1 \mathrm{wt} \%$, which renewed a great interest in the $\mathrm{Ni}_{3} \mathrm{Al}$-based superalloys. Oak Ridge National Laboratory (ORNL) brought together over than 100 research institutes and launched a research program on intermetallic alloys. Thus, a number of commercial $\mathrm{Ni}_{3} \mathrm{Al}$-based intermetallic alloys were developed and introduced to various branches of industry in the past decades and attracted more and more attentions in recent years.

Liu et al. [9-11] proposed a family of intermetallic compounds (IC) of series $\mathrm{Ni}_{3} \mathrm{Al}$-based alloys, substituting 8 at. $\% \mathrm{Cr}$ for 4 at.\% $\mathrm{Al}$ into the $\mathrm{Ni}_{3} \mathrm{Al}$ phase with small additions of $\mathrm{Hf}, \mathrm{Zr}$, Mo and Ti to improve the mechanical properties at elevated temperatures. Thereafter, a number of other $\mathrm{Ni}_{3} \mathrm{Al}$-based superalloys were designed and studied [12-18]. Zhang et al. [12] reported the as-cast and hightemperature microstructures of two polycrystalline $\mathrm{Ni}_{3} \mathrm{Al}-$ based superalloys, i.e., MX246 and MX246A; Han et al. studied the heat treatment microstructure and mechanical properties of the directionally solidificated (DS) $\mathrm{Ni}_{3} \mathrm{Al}-$ based superalloy IC6 [13] and single-crystal (SC) $\mathrm{Ni}_{3} \mathrm{Al}-$ based superalloy IC6SX [14]; Zhang et al. [15] studied the flow behaviors of a DS $\mathrm{Ni}_{3} \mathrm{Al}$-based superalloy IC10; Gong et al. [16-18] investigated the heat treatment microstructure, stress rupture properties and oxidation resistance of $\mathrm{SC} \mathrm{Ni}_{3} \mathrm{Al}$-based superalloy IC21. However, the majority of the previous works [19-28] are mainly focused on the composition design, processing technologies and mechanical properties; little attention was paid on the microstructural investigation, especially for casting polycrystalline $\mathrm{Ni}_{3} \mathrm{Al}$-based superalloys [12]. Moreover, in consideration of its difficulty in characterization of the various $\gamma^{\prime}$ phases, limited reports about the microstructural characterization of $\mathrm{Ni}_{3} \mathrm{Al}$-based alloy can be found $[13,22,23,26]$. Generally, $\mathrm{Ni}_{3} \mathrm{Al}$-based alloys are prepared through casting technology, and it usually involves series of intermetallic phase transformations during the solidification. For this reason, understanding the precipitation behaviors involved during solidification process is vitally valuable for the design of casting technology $[14,15,19,22]$.

Although many studies have been reported about the popular $\mathrm{Ni}_{3} \mathrm{Al}$-based alloys, no systematic efforts have been carried out to investigate the intermetallic phase transformations involved during solidification process combined with microstructural characterization. In addition, the original as-cast microstructure has significant influences on the subsequent microstructural evolution during heat treatment, which is meaningful to be studied. Therefore, in the present work, by adding moderate $\mathrm{W}$ (1.5-2.5 wt\%), Mo (3.5-5.5 wt\%) and $\mathrm{Hf}(0.3-0.9 \mathrm{wt} \%)$ to enhance the elevated temperature properties, accompanied by higher Fe content $(<2 \mathrm{wt} \%)$ to improve the weldability, a newly polycrystalline $\mathrm{Ni}_{3} \mathrm{Al}$-based superalloy was designed and applied to investigate the as-cast microstructure by optical microscopy (OM), scanning electron microscopy (SEM) as well as transmission electron microscopy (TEM) equipped with selected area diffraction (SAD) system; the intermetallic phase transformation sequences during heating and cooling processes are determined based on differential scanning calorimetry (DSC) measurements; the precipitation behaviors involved during solidification are discussed and schematic expressed in detail.

\section{Experimental}

The $\mathrm{Ni}_{3} \mathrm{Al}$-based superalloy used in this work was an ascasted ingot produced by vacuum induction melting (VIM) and electroslag remelting (ESR) techniques with a diameter of 150 and $68 \mathrm{~mm}$ in height, and its chemical composition (wt\%) is listed in Table 1. To investigate the microstructure of the as-cast $\mathrm{Ni}_{3} \mathrm{Al}$-based superalloy, cylindrical samples with a diameter of 3 and $6 \mathrm{~mm}$ in height were prepared by wire electrical discharge machining (WEDM). The mechanically polished samples were chemically etched for $0.5 \mathrm{~s}$ with a solution containing $5 \mathrm{~g}$ $\mathrm{CrO}_{3}+10 \mathrm{ml} \mathrm{H}_{2} \mathrm{O}+30 \mathrm{ml} \mathrm{HCl}$ at room temperature. The microstructure was examined by OM, SEM and TEM equipped with SAD. SEM observation was conducted on a S4800 microscope operated at $15 \mathrm{kV}$. In order to analyze the $\gamma^{\prime}$ phase morphology, TEM observations were performed on a JEM-2100F microscope with the voltage of $200 \mathrm{kV}$. Samples for TEM observations were firstly machined from the as-cast ingot and then grinded into 40to $60-\mu \mathrm{m}$-thick foils. Subsequently, some disks with $3 \mathrm{~mm}$ in diameter were punched out from the grinded thin foils and then electro-polished using a solution of $5 \%$ 
Table 1 Chemical composition of $\mathrm{Ni}_{3} \mathrm{Al}$-based superalloy (wt $\%$ )

\begin{tabular}{|c|c|c|c|c|c|c|c|c|c|c|c|}
\hline $\mathrm{Al}$ & $\mathrm{Cr}$ & Mo & W & $\mathrm{C}$ & $\mathrm{Si}$ & Hf & B & $\mathrm{Mn}$ & $\mathrm{Ti}$ & $\mathrm{Fe}$ & $\mathrm{Ni}$ \\
\hline $7.6-8.5$ & $7.4-8.2$ & $3.5-5.5$ & $1.5-2.5$ & $0.06-0.20$ & $<0.5$ & $0.3-0.9$ & $<0.05$ & $<0.5$ & $0.6-1.2$ & $<2$ & Bal. \\
\hline
\end{tabular}

$\mathrm{HClO}_{3}+95 \% \mathrm{C}_{2} \mathrm{H}_{5} \mathrm{OH}$ (by volume) at the temperature in the range of $-25{ }^{\circ} \mathrm{C}$ and $20^{\circ} \mathrm{C}$ with the voltage of $40 \mathrm{~V}$. DSC experiments were performed on a Mettler Toledo TGA/DSC 1 by heating from 25 to $1500{ }^{\circ} \mathrm{C}$ under the heating rate of $10^{\circ} \mathrm{C} / \mathrm{min}$ and then cooled to room temperature at the cooling rate of $-10{ }^{\circ} \mathrm{C} / \mathrm{min}$ in the $\mathrm{Ar}$ atmosphere, and the tested sample was cut from the as-cast bulk ingot with a weight of $30.7 \mathrm{mg}$. Image Pro-Plus software 6.0 was applied to measure size and volume fraction of the intermediate particles.

\section{Results and Discussion}

\subsection{Microstructural Characterization of the As-Cast $\mathrm{Ni}_{3} \mathrm{Al}$-Based Superalloy}

\subsubsection{Morphology of Dendritic and Interdendritic Phases}

Figure 1 shows the $\mathrm{OM}$ morphology of the as-cast $\mathrm{Ni}_{3} \mathrm{Al}-$ based superalloy. The microstructure exhibits the kind of terraced feature. The as-cast microstructure consists of two distinct regions: the dominating bright branches are determined to be the dendritic regions, whereas the interspersed dark stripes are identified as the interdendritic regions $[12,29]$. Besides, the volume fraction of dendritic and interdendritic regions in the as-cast microstructure is measured to be about 80.63 and $19.37 \%$, respectively. The $\mathrm{Ni}_{3} \mathrm{Al}$-based superalloy contains a larger portion of eutectic regions compared to that $18 \%$ in the as-cast MX246 alloy

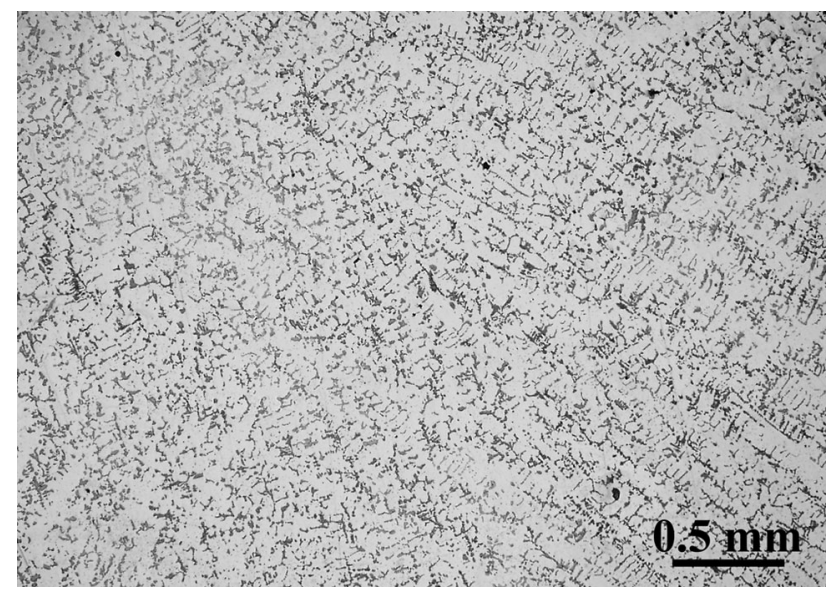

Fig. $1 \mathrm{OM}$ morphology of as-cast $\mathrm{Ni}_{3} \mathrm{Al}$-based superalloy and $4 \%$ in the as-cast MX246A alloy [12], along with 6.5\% $\gamma+\mathrm{Ni}_{5} \mathrm{Zr}$ eutectic constituents in the as-cast IC221M alloy [30]. Moreover, the eutectic regions in this alloy exhibit a kind of diverse characteristics from above studies.

The corresponding SEM images under different magnifications are shown in Fig. 2. As shown in Fig. 2a, the ascast microstructure consists of distinct dendritic and interdendritic regions, as marked by the arrows, respectively. The integral interdendrites can be observed to distribute randomly and possess parallel orientation in limited regions. Figure $2 b$ demonstrates a dendritic and eutectic structure [12], and the magnified morphologies are exhibited in Fig. 2c, d, respectively.

As illustrated in the magnified morphology of dendrite in Fig. 2c, plenty of cuboidal $\gamma^{\prime}$ precipitates are distributed uniformly, and the mean size is estimated to about $0.48 \mu \mathrm{m}$. The dendrite exhibits a masonry-wall-like morphology, where $\gamma^{\prime}$ phase precipitates coherently from supersaturated $\gamma$ phase, in shape of irregular cube possessing four diverse faces, inlaying with each other matching up to their geometric profile. Thus, the cuboidal $\gamma^{\prime}$ precipitates can be treated to act as the bricks, and there exist $\gamma$-channels between two adjacent $\gamma^{\prime}$ precipitates, where ultrafine particles are dispersively distributed. The average width of the $\gamma$-channels is about $0.05 \mu \mathrm{m}$. Figure $2 \mathrm{~d}$ displays the magnified SEM morphology of the eutectic structure, where some quasi-spherical particles are observed. The quasi-spherical particles emerge a kind of linear arrays as well as scattered distribution in the eutectic structure. The SEM morphologies of the explored as-cast $\mathrm{Ni}_{3} \mathrm{Al}$-based superalloy have been presented as above, and the cuboidal $\gamma^{\prime}$ precipitates within dendrite are clearly demonstrated, while the particles distributing within $\gamma$ channels and eutectic structure cannot be qualitatively identified, which will be determined by the following TEM observation.

\subsubsection{TEM Characterization of the Dendrite}

In order to further determine the crystal structure of the ultrafine particles distributed within the $\gamma$-channels between adjacent $\gamma^{\prime}$ precipitates in the dendrite, TEM observation was carried out, and the corresponding images coupled with SAD patterns in the zone axis parallel to $[110]_{\gamma^{\prime}}$ and $[100]_{\gamma}$ are shown in Fig. 3. As indicated in Fig. 3a, $\gamma^{\prime}$ phase precipitates coherently with cuboidal 

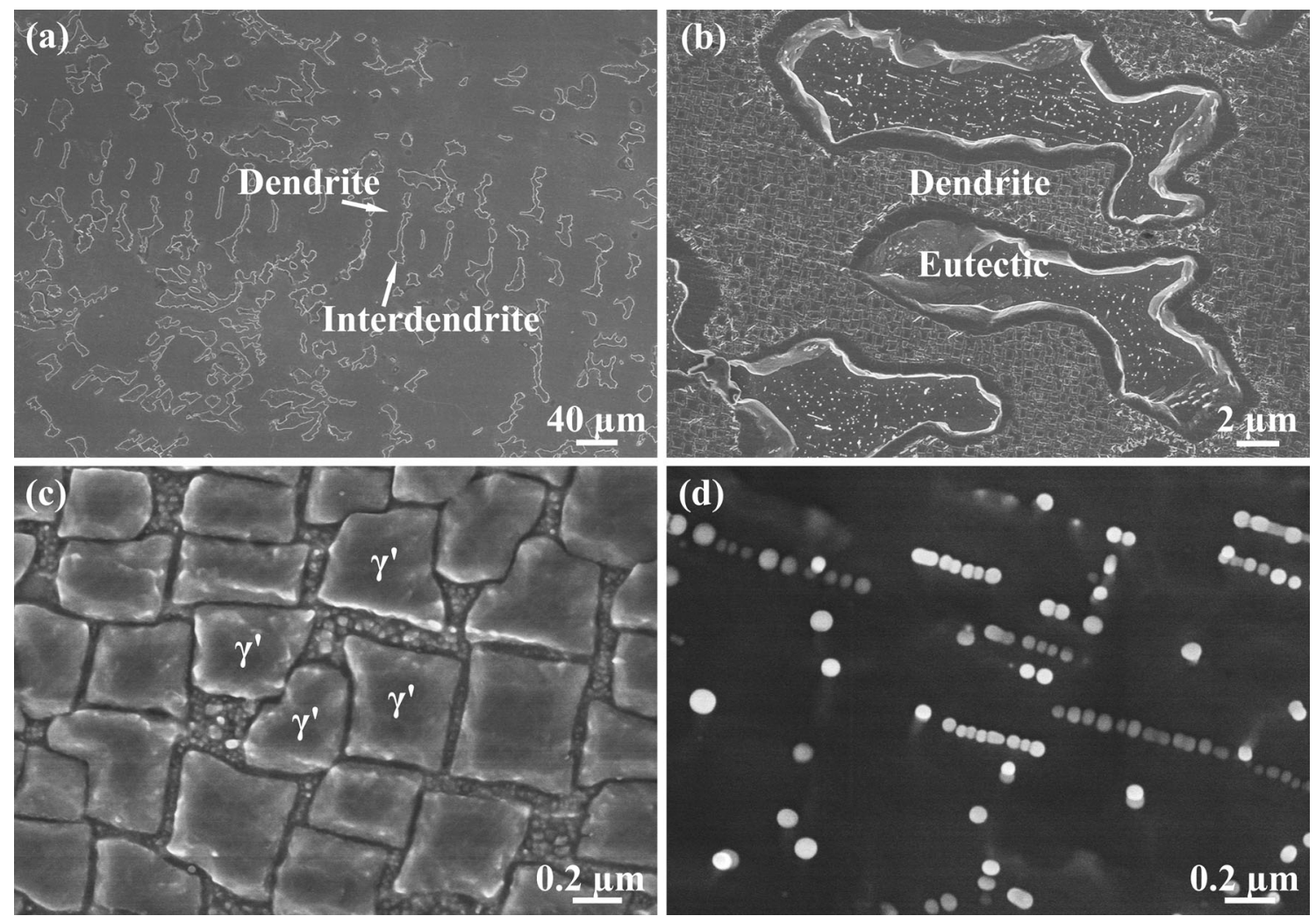

Fig. 2 SEM morphologies of as-cast $\mathrm{Ni}_{3} \mathrm{Al}$-based superalloy: a dendritic and interdendritic regions; $\mathbf{b}$ dendritic and eutectic structure; $\mathbf{c}$ cuboidal $\gamma^{\prime}$ precipitates in dendrite; $\mathbf{d}$ quasi-spherical ultrafine particles in eutectic structure
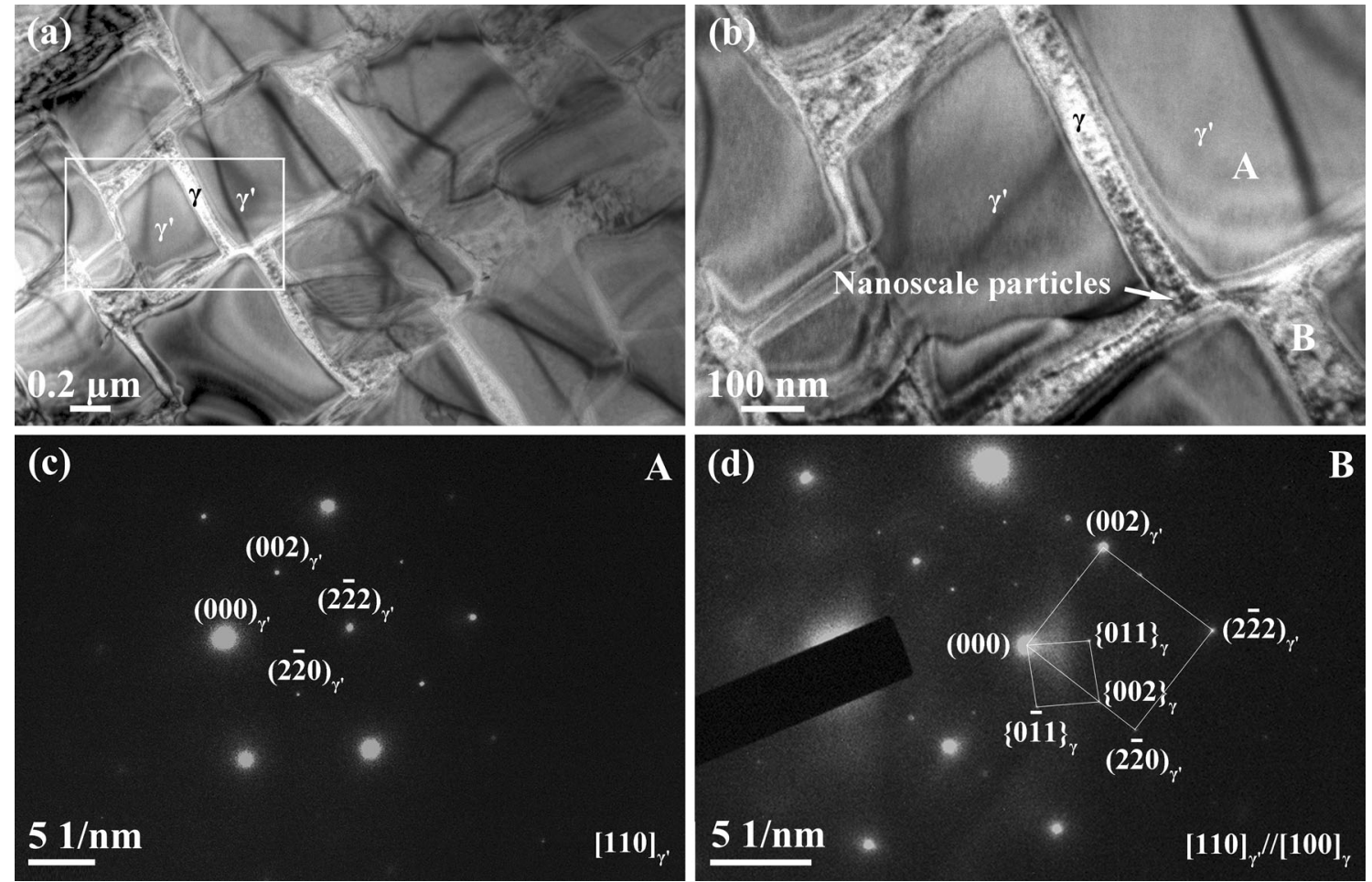

Fig. 3 TEM bright-field images for dendrite at low $\mathbf{a}$ and high $\mathbf{b}$ magnification, corresponding SAD patterns for marked areas of $A \mathbf{c}$ and $B \mathbf{d}$ in b (the zone axis is parallel to $[110]_{\gamma^{\prime}}$ and $[100]_{\gamma}$ ) 
morphology in the obtained TEM bright-field image for the dendrite, in good agreement with the SEM image of Fig. 2c. As shown in Fig. 3b, which is the magnified TEM image of the marked rectangular region in Fig. 3a, two adjacent $\gamma^{\prime}$ precipitates are separated by $\gamma$-phase channels, and there is apparent boundary between the $\gamma$-channel and $\gamma^{\prime}$ precipitate. Besides, a plenty of nanoscale particles are homogenously precipitated within the $\gamma$-channel.

To analyze the crystal structure of the nanoscale particles, the SAD patterns are acquired. Figure $3 \mathrm{c}$ shows the corresponding SAD patterns in the zone axis parallel to $[110]_{\gamma^{\prime}}$ for the marked A area in Fig. 3b, which obviously proves its $\mathrm{L}_{2}$ structure of the cuboidal $\gamma^{\prime}$ phase [31]. As for the corresponding SAD patterns for the marked B area, Fig. $3 \mathrm{~d}$ reveals two disparate types of crystal structure corresponded to $\gamma$ phase and $\gamma^{\prime}$ phase, respectively. Hence, it can be inferred that there is $\gamma^{\prime}$ phase within the $\gamma$-channel between cuboidal $\gamma^{\prime}$ precipitates, and the ultrafine nanoscale particles can be determined as a diverse kind of $\gamma^{\prime}$ phase. It can be concluded that the dendrite is composed of quasi-cuboidal $\gamma^{\prime}$ precipitates connected by $\gamma$-channels where ultrafine $\gamma^{\prime}$ particles are distributed, so the dendrite can be defined as $\gamma^{\prime}+\gamma$ dendrite.

\subsubsection{TEM Characterization of the Interdendrite}

From the SEM morphology of Fig. 2d, a number of quasispherical particles are observed within the eutectic structure, i.e., interdendritic region. To precisely determine its morphology and crystal structure, TEM observations associated with SAD patterns were conducted and are shown in Fig. 4. In the bright-field image of the eutectic structure shown in Fig. 4a, a number of coherent quasispherical particles are observed, which is counted to be about $60 \mathrm{~nm}$ in mean diameter indicated by the arrows. Moreover, the particles tend to exist in linear arrays, as marked by the dotted line, consistent with the morphology in Fig. 2d. In the magnified image of Fig. 4b, its quasispherical morphology can be seen more clearly; in addition, some tiny particles are discovered unexpectedly, as indicated by the black arrows. The tiny particles are supposed to precipitate from the supersaturated $\gamma$ phase during the solidification process. Figure $4 \mathrm{c}$ shows the SAD patterns for the selected $\mathrm{C}$ area in Fig. 4b, which reveals its $\gamma$ phase characteristic. Otherwise, the SAD patterns for the $\mathrm{D}$ particle prove the quasi-spherical particles to be $\gamma^{\prime}$ phase. Therefore, the interdendrite is characterized as $\gamma^{\prime}-\gamma$ eutectic structure comprising $\gamma$ phase and dotted quasi-spherical $\gamma^{\prime}$ particles.

\subsection{Phase Separation Sequences During Solidification Process}

\subsubsection{Determination of Transformation Sequences}

DSC results of the as-cast $\mathrm{Ni}_{3} \mathrm{Al}$-based superalloy are presented in Fig. 5. Three endothermic peaks emerged during heating from 900 to $1500{ }^{\circ} \mathrm{C}$, which reveals the three-stage transformations. A slightly endothermic peak (Endo.1) firstly appears around the temperature of $1117{ }^{\circ} \mathrm{C}$, which corresponds to the peak temperature for $\gamma^{\prime}$ phase solid-dissolved into $\gamma$ phase. Then, the second endothermic peak (Endo.2) appears when heated to $1349{ }^{\circ} \mathrm{C}$, which corresponds to the peak temperature for the melting of $\gamma^{\prime}-\gamma$ eutectic phases. Subsequently, when heated to $1356{ }^{\circ} \mathrm{C}$ in the following heating procedure, another unobvious endothermic peak (Endo.3) appears, which can be identified as the peak temperature for $\gamma$ phase melting. During the continuous heating higher than $1356^{\circ} \mathrm{C}$, the solid $\gamma$ phase will be gradually melted into liquidoid. Thus, it can be observed that the peak temperatures for melting of $\gamma^{\prime}-\gamma$ eutectic and $\gamma$ phase are very close. According to the above results, the $\gamma^{\prime}-\gamma$ eutectic is characterized as dominating $\gamma$ phase with some dotted $\gamma^{\prime}$ precipitates, so the closed melting temperatures indicated by Endo. 2 and Endo. 3 can be attributed to their similar phase constituent.

For the subsequent cooling process from $1500{ }^{\circ} \mathrm{C}$ (i.e., the solidification process), it exhibited four apparent exothermic peaks. An exothermic peak (Exo.1) firstly arises around the temperature of $1348{ }^{\circ} \mathrm{C}$, and the exothermic peak can be identified as the peak temperature for $\gamma$ phase nucleation from liquidoid. Compared to the heating process, the peak nucleation point for $\gamma$ phase $\left(1348{ }^{\circ} \mathrm{C}\right)$ is slightly lower than its peak melting point $\left(1356^{\circ} \mathrm{C}\right)$. Afterward, a second exothermic peak (Exo.2) arises when cooled to around $1326{ }^{\circ} \mathrm{C}$, which corresponds to the peak temperature for the generation of $\gamma^{\prime}-\gamma$ eutectic structure from residual liquidoid. Then, a distinct exothermic peak (Exo.3) emerges around $1190{ }^{\circ} \mathrm{C}$, based on the above TEM results; it can be inferred to the peak temperature for the cuboidal $\gamma^{\prime}$ phase precipitation (Figs. 2c, 3a) from $\gamma$ phase, which can be defined as $\gamma_{\mathrm{I}}^{\prime}$. At last, the fourth exothermic peak (Exo.4) appears around $1043{ }^{\circ} \mathrm{C}$. Due to the results presented in Fig. 3, nanoscale $\gamma^{\prime}$ particles are dispersedly distributed within the $\gamma$-phase channels between two cuboidal $\gamma_{\text {I }}^{\prime}$ precipitates, which can be regarded to precipitate behind $\gamma_{\mathrm{I}}^{\prime}$. Herein, the nanoscale $\gamma^{\prime}$ particles are defined as $\gamma_{\mathrm{II}}^{\prime}$, and the exothermic peak around $1043{ }^{\circ} \mathrm{C}$ can be explained as the peak temperature for the precipitation of $\gamma_{\text {II }}^{\prime}$ phase. Besides, an obvious endothermic peak appears around $1166^{\circ} \mathrm{C}$, as marked by the asterisk on the cooling curve, which is unknown and needs further confirmation. 

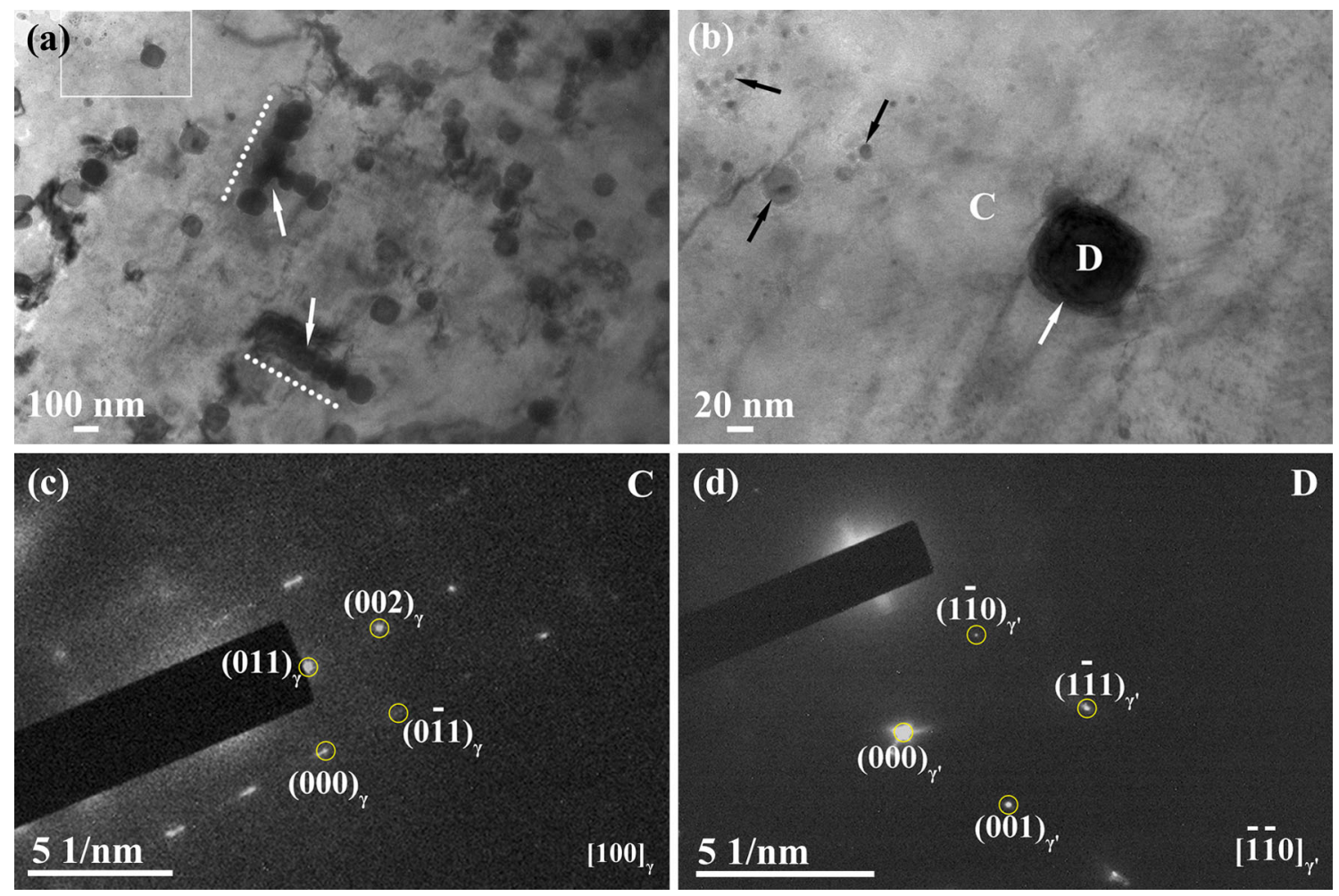

Fig. 4 TEM bright-field images for eutectic structure at low $\mathbf{a}$ and high $\mathbf{b}$ magnification, corresponding SAD patterns for marked areas of $C \mathbf{c}$ and $\mathrm{D} \mathbf{d}$ in $\mathbf{b}$ (the zone axis is parallel to $[100]_{\gamma}$ and $[\overline{1} \overline{1} 0]_{\gamma^{\prime}}$

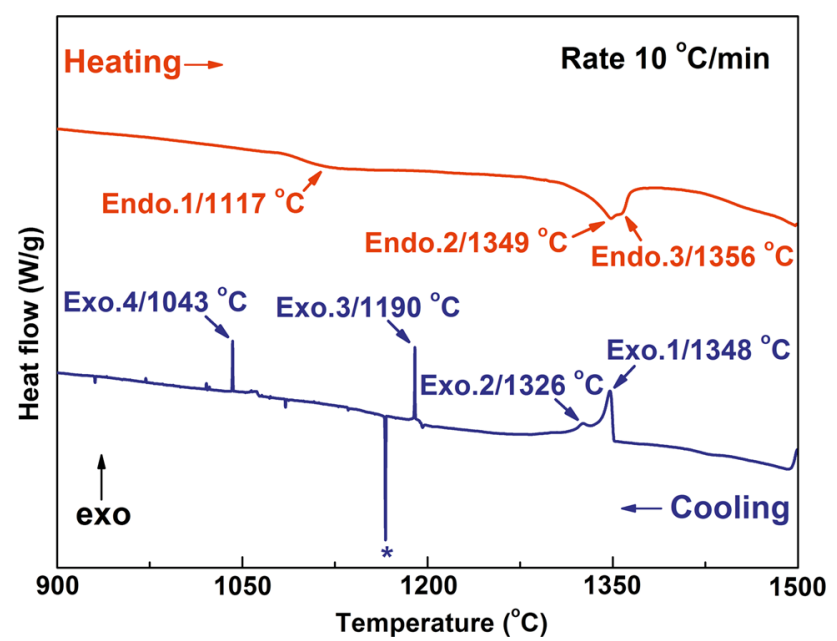

Fig. 5 DSC results of as-cast $\mathrm{Ni}_{3} \mathrm{Al}$-based superalloy (Exo. and Endo. represent exothermic and endothermic peaks, respectively)

\subsubsection{Precipitation Behavior of Intermetallic Phases During Solidification Process}

Based on the above experimental results of the as-cast $\mathrm{Ni}_{3} \mathrm{Al}$-based superalloy, the precipitation process of intermetallic phases during solidification has been determined and interpolated by the schematic diagrams shown in Fig. 6. When cooled to the temperature lower than the onset temperature for $\gamma$ phase nucleation, a portion of liquidoid will be transformed into $\gamma_{\mathrm{D}}$ phase, leading to the generation of dendrite. Meanwhile, the residual liquidoid will be surrounded by the $\gamma_{\mathrm{D}}$ phase, as indicated in Fig. 6a. As the temperature lowers to eutectic line, the residual liquidoid is transformed into interdendritic phases, which is identified as the eutectic structure consisting of dotted quasi-spherical $\gamma_{\mathrm{E}}^{\prime}$ coupled with $\gamma_{\mathrm{E}}$ phase, and part of the quasi-spherical $\gamma_{\mathrm{E}}^{\prime}$ precipitates seem to exhibit linear arrays in orientation, as presented in Fig. $6 b$.

Afterward, it primarily involves the precipitation of $\gamma^{\prime}$ phase in the dendritic region, i.e., the $\gamma_{\mathrm{D}}$ phase. Once it decreases to the onset temperature for $\gamma^{\prime}$ phase near Exo.3, $\gamma^{\prime}$ phase will be motivated to precipitate from the $\gamma_{\mathrm{D}}$ phase. During the following continuous cooling process, plentiful $\gamma^{\prime}$ nucleus is generated from the $\gamma_{D}$-matrix and grown rapidly in irregularly cuboidal morphology, resulting in the homogeneously distributed massive $\gamma^{\prime}$ precipitates (Fig. 2c). According to the DSC results, there is a secondary exothermic peak (Exo.4) for $\gamma^{\prime}$ precipitation under the temperature lower than Exo.3; therefore, the irregularly cuboidal $\gamma^{\prime}$ precipitates are marked as $\gamma_{\mathrm{I}}^{\prime}$ phase. As a consequence, part of the $\gamma_{\mathrm{D}}$ phase in the dendritic region is transformed into $\gamma_{\text {I }}^{\prime}$ phase, as approximatively expressed in Fig. 6c. With the precipitation of $\gamma_{I}^{\prime}$ 

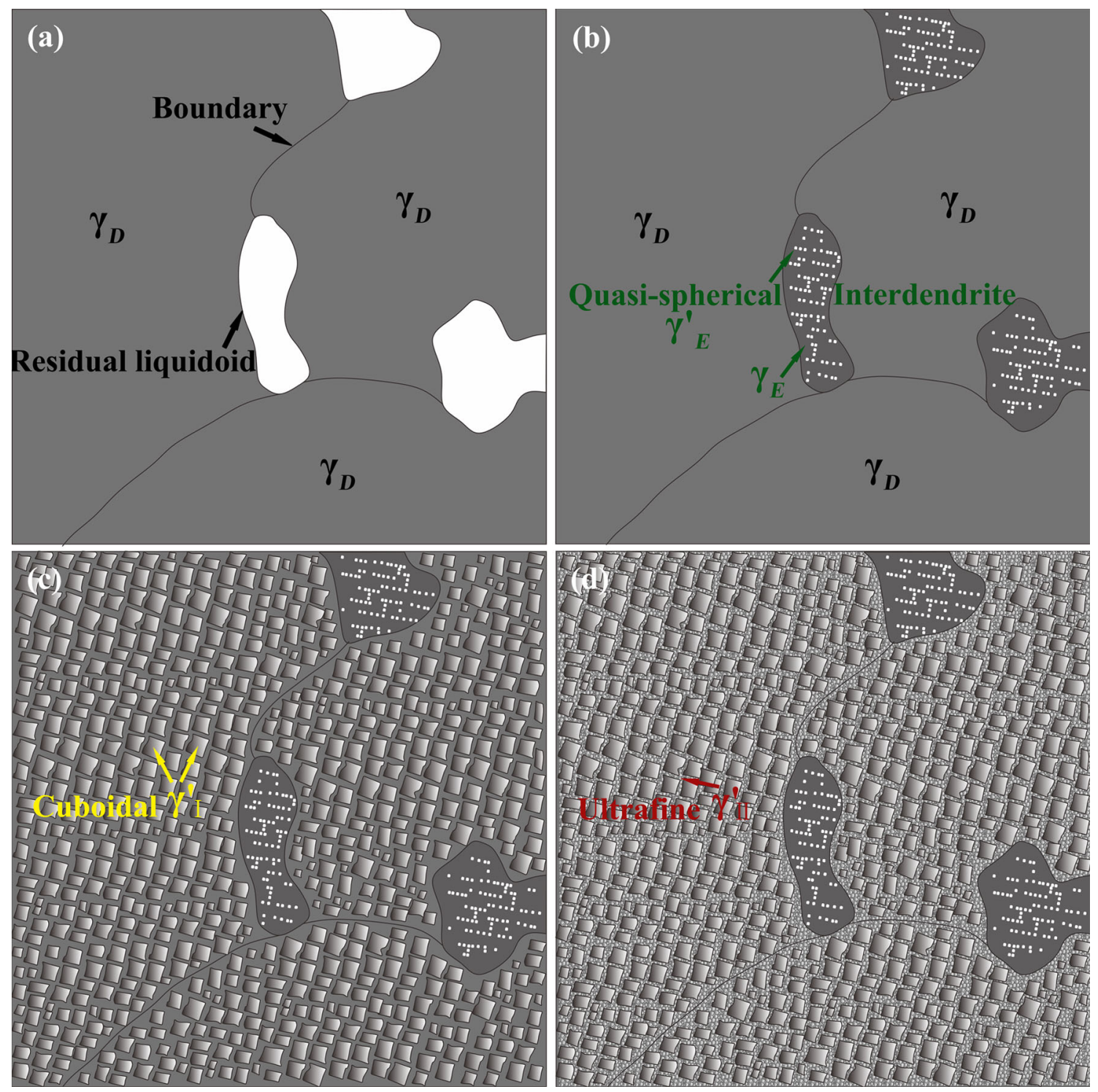

Fig. 6 Schematic diagrams for precipitation process of intermetallic phases during solidification in as-cast $\mathrm{Ni}_{3} \mathrm{Al}$-based superalloy $\left(\gamma_{\mathrm{D}}\right.$ : dendritic $\gamma$ phase firstly precipitated from the liquidoid; $\gamma_{\mathrm{E}}^{\prime}$ : quasi-spherical eutectic $\gamma^{\prime}$ phase precipitated from the residual liquidoid, $\gamma_{\mathrm{E}}$ : eutectic $\gamma$ phase precipitated from residual liquid, $\gamma_{\mathrm{I}}^{\prime}$ : the primary cuboidal $\gamma^{\prime}$ phase precipitated from $\gamma_{\mathrm{D}}$ phase, $\gamma_{\mathrm{II}}^{\prime}$ : ultrafine secondary $\gamma^{\prime}$ phase precipitated from the $\gamma_{\mathrm{D}}$-channels): a first generation of $\gamma_{\mathrm{D}}$ dendrite from liquidoid near $1348{ }^{\circ} \mathrm{C}$; $\mathbf{b}$ subsequent transformation of $\gamma_{\mathrm{E}}^{\prime}-\gamma_{\mathrm{E}}$ interdendrite from the residual liquidoid near $1326^{\circ} \mathrm{C}$; c precipitation of cuboidal $\gamma_{\mathrm{I}}^{\prime}$ phase from $\gamma_{\mathrm{D}}$ dendrite near $1190{ }^{\circ} \mathrm{C}$; d precipitation of nanoscale $\gamma_{I I}^{\prime}$ phase from the $\gamma_{\mathrm{D}}$-channels near $1043{ }^{\circ} \mathrm{C}$

phase, the original $\gamma_{\mathrm{D}}$ phase is divided into narrow channels located between $\gamma_{\mathrm{I}}^{\prime}$ precipitates, and when cooled to the temperature near Exo.4 (Fig. 5), the secondary $\gamma^{\prime}$ phase signed as $\gamma_{\text {II }}^{\prime}$ phase precipitates within the $\gamma$-channels. According to the SAD results in Fig. 3d, the ultrafine $\gamma_{\mathrm{II}}^{\prime}$ phase can be certified and is schematically displayed in Fig. 6d. Finally, microstructure of the as-cast $\mathrm{Ni}_{3} \mathrm{Al}$-based superalloy can be characterized as interdendritic region, i.e., $\gamma^{\prime}-\gamma$ eutectic structure consisting of $\gamma_{E}$ phase with dotted quasi-spherical $\gamma_{E}^{\prime}$ particles and dendritic region composed of quasi-cuboidal $\gamma_{\mathrm{I}}^{\prime}$ phase surrounded by $\gamma_{\mathrm{II}}^{\prime}-\gamma-$ channels.

\section{Conclusions}

In the present work, the as-cast microstructure of a designed polycrystalline $\mathrm{Ni}_{3} \mathrm{Al}$-based superalloy is characterized by OM, SEM, TEM equipped with SAD system, and the intermetallic phase transformations involved during solidification process are determined based on DSC measurements. Some important conclusions can be summarized as follows:

1. The as-cast microstructure of the $\mathrm{Ni}_{3} \mathrm{Al}$-based superalloy is mainly composed of $80.63 \mathrm{vol} \%$ dendritic and 
$19.37 \mathrm{vol} \%$ interdendritic phases. The dendrite is identified as quasi-cuboidal $\gamma_{\mathrm{I}}^{\prime}$ phase connected by $\gamma$ channels where ultrafine $\gamma_{\text {II }}^{\prime}$ particles are distributed, and the interdendrite is determined as $\gamma^{\prime}-\gamma$ eutectic structure consisting of $\gamma_{E}$ phase with dotted quasispherical $\gamma_{\mathrm{E}}^{\prime}$ particles.

2. During solidification, the dendrite firstly generated from liquidoid near $1348{ }^{\circ} \mathrm{C}$; subsequently, the residual liquidoid will be transformed into interdendritic phases around $1326^{\circ} \mathrm{C}$. Afterward, $\gamma^{\prime}$ phase will precipitate from dendritic $\gamma$-matrix with two-stage characteristics, resulting in the distinct precipitation of $\gamma_{\mathrm{I}}^{\prime}$ and $\gamma_{\mathrm{II}}^{\prime}$ phases when approaching to 1190 and $1043{ }^{\circ} \mathrm{C}$, respectively.

Acknowledgements The work was financially supported by the National Natural Science Foundation of China (Nos. U1660201 and 51474156), the China National Funds for Distinguished Young Scientists (No. 51325401) and the National High Technology Research and Development Program of China (No. 2015AA042504).

\section{References}

[1] P. Jozwik, W. Polkowski, Z. Bojar, Materials 8, 2537 (2015)

[2] V.K. Sikka, J.T. Mavity, K. Anderson, Mater. Sci. Eng. A 153, $712(1992)$

[3] X.S. Zhou, C.X. Liu, L.M. Yu, Y.C. Liu, H.J. Li, J. Mater. Sci. Technol. 31, 235 (2015)

[4] J.H. Westbrook, J. Met. 209, 898 (1957)

[5] J.X. Zhang, T. Murakumo, Y. Koizumi, T. Kobayashi, H. Harada, Metall. Mater. Trans. A 35, 1911 (2004)

[6] X. Peng, S.M. Jiang, J. Gong, X.D. Sun, C. Sun, J. Mater. Sci. Technol. 32, 587 (2016)

[7] X.Y. Chen, Y.Z. Zhou, T. Jin, X.F. Sun, J. Mater. Sci. Technol. 32, 177 (2016)
[8] K. Aoki, O. Izumi, J. Jpn. Inst. Met. 43, 1190 (1979)

[9] C.T. Liu, C.L. White, J.A. Horton, Acta Metall. 33, 213 (1985)

[10] C.T. Liu, V.K. Sikka, JOM 38(5), 19 (1986)

[11] C.T. Liu, V.K. Sikka, U.S. Patent 5,006,308, 9 Apr 1991

[12] X.E. Zhang, H.L. Luo, S.P. Li, X. Cao, S.Q. Li, J. Iron. Steel Res. Int. 14(5), 45 (2007)

[13] Y.F. Han, S.H. Li, Y. Jin, M.C. Chaturvedi, Mater. Sci. Eng. A 192, 899 (1995)

[14] P. Li, S.S. Li, Y.F. Han, Intermetallics 19, 182 (2011)

[15] H. Zhang, W. Wen, H. Cui, Mater. Sci. Eng. A 504, 99 (2009)

[16] D.L. Cui, X.Y. Xie, S.S. Li, H. Zhang, S.K. Gong, Mater. Sci. Forum 747, 665 (2013)

[17] X.J. Xu, Q. Wu, S.K. Gong, S.S. Li, Mater. Sci. Forum 747, 582 (2013)

[18] H. Li, F.L. Li, S.S. Li, H. Zhang, S.K. Gong, Mater. Sci. Forum 747, 659 (2013)

[19] Y.F. Li, J.T. Guo, L.Z. Zhou, H.Q. Ye, Mater. Lett. 58, 1853 (2004)

[20] D.B. Lee, M.L. Santella, Mater. Sci. Eng. A 374, 217 (2004)

[21] L. Cao, L. Yao, Y.Z. Zhou, T. Jin, X.F. Sun, J. Mater. Sci. Technol. 33(4), 347 (2017).

[22] J. Lapin, Intermetallics 5, 615 (1997)

[23] H. Li, L. Zheng, H. Zhang, S. Li, H. Zhang, S. Gong, Procedia Eng. 27, 1187 (2012)

[24] L.W. Jiang, M.L. Wu, S.S. Li, Y.F. Han, Mater. Res. Innov. 19, S163 (2015)

[25] W. Polkowski, P. Jóźwik, Z. Bojar, J. Alloys Compd. 614, 226 (2014)

[26] J. Lapin, S. Wierzbinski, T. Pelachova, Intermetallics 7, 705 (1999)

[27] B. Binesh, A.J. Gharehbagh, J. Mater. Sci. Technol. 32, 1137 (2016)

[28] S.A. David, W.A. Jemian, C.T. Liu, J.A. Horton, Weld. J. 64(1), 22 (1985)

[29] L.W. Jiang, S.S. Li, M.L. Wu, Y.F. Han, Mater. Sci. Forum 747, 797 (2013)

[30] D. Lee, Met. Mater. Int. 12, 153 (2006)

[31] Y. Amouyal, Z. Mao, D.N. Seidman, Appl. Phys. Lett. 93, 372 (2008) 